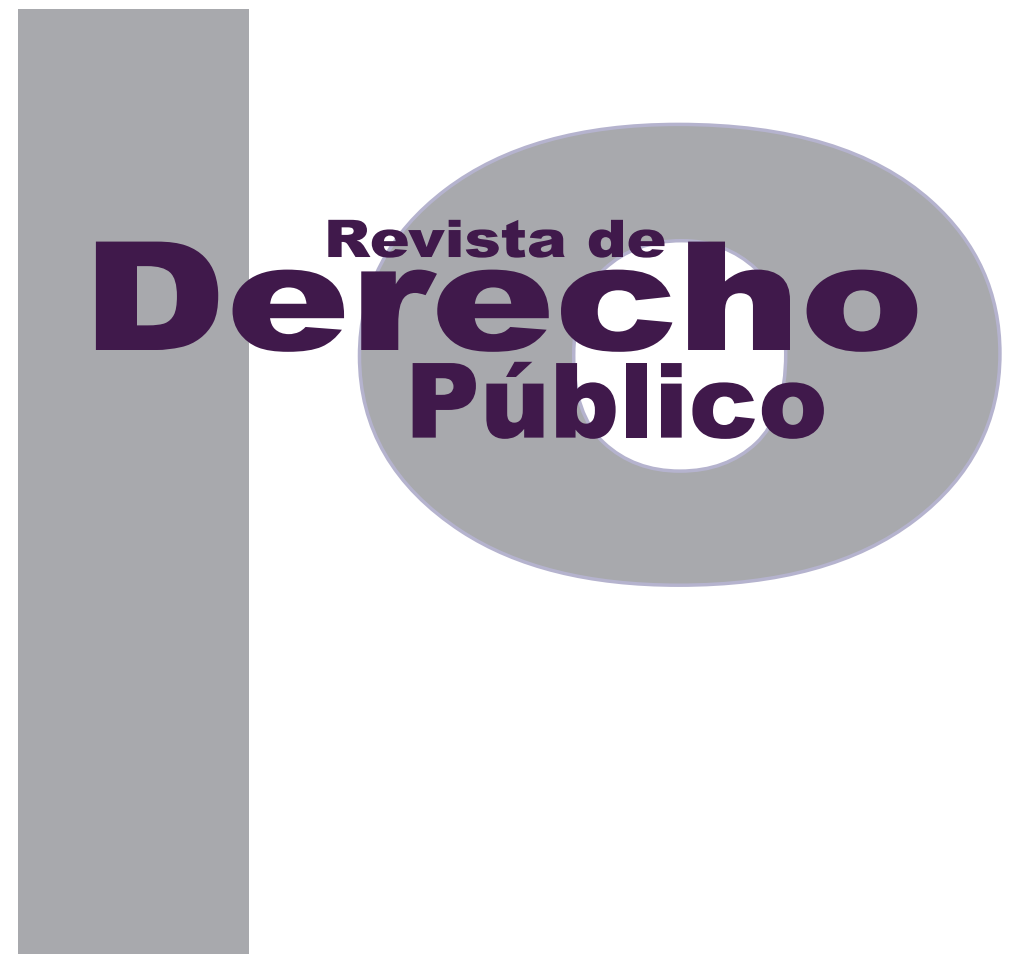

\title{
CONSIDERACIONES SOBRE LA VERDAD EN EL DISCURSO NORMATIVO
}

\author{
DAVID JOSÉ BLANCO CORTINA
}

Artículo de reflexión

DOI: http://dx.doi.org/10.15425/redepub.33.2014.23

Universidad de los Andes

Facultad de Derecho

Revista de Derecho Público N. ${ }^{\circ} 33$

Julio - Diciembre de 2014. ISSN 1909-7778 


\section{Consideraciones sobre la verdad en el discurso normativo}

\section{Resumen}

El presente artículo es un intento por esclarecer la pregunta acerca de las condiciones bajo las cuales se puede hablar de verdad en el mundo del derecho, desarrollando una hipótesis como respuesta tentativa al respecto. El esclarecimiento de la pregunta viene dado por la precisión de los conceptos que componen el problema: verdad y derecho. La hipótesis planteada consiste en afirmar que se puede hablar de verdad en el derecho desde dos perspectivas diferentes: i) la lógica de proposiciones normativas y ii) la cuestión de la prueba judicial o premisa fáctica del razonamiento judicial. En el presente texto se profundizará la primera de las perspectivas.

Palabras clave: verdad, derecho, normas, proposiciones normativas.

\section{Considerations about the truth in the normative discourse}

\section{Abstract}

This article tries to clarify the question about when we can say there is truth in law. For this, we will discuss the next hypothesis: we can talk about truth in law in two ways: how normative propositions and the scope of legal proof. But before we must define two notions: law and truth. This essay will deepen the perspective concerning normative propositions.

Keywords: truth, law, rules and normative propositions.

\section{Considerações sobre a verdade no discurso normativo}

\section{Resumo}

O presente artigo é uma tentativa de esclarecer a pregunta sobre as condições sob as quais se pode falar de verdade no mundo do direito, desenvolvendo uma hipótese como resposta tentativa a respeito. 0 esclarecimento da pergunta vem dado pela precisão dos conceitos que compõem o problema: verdade e direito. A hipótese levantada consiste em afirmar que se pode falar de verdade no direito desde duas perspectivas diferentes: i) a lógica de proposições normativas e ii) a questão da prova judicial ou premissa fática do raciocínio judicial. No presente texto será aprofundada a primeira das perspectivas.

Palavras-chave: verdade, direito, normas, proposições normativas. 


\title{
Consideraciones sobre la verdad en el discurso normativo*
}

\author{
David José Blanco Cortina*
}

\section{SUMARIO}

Introducción - I. LA DISPUTA POR LA DISTINCIÓN ENTRE NORMAS Y PROPOSICIONES NORMATIVAS - A. Las versiones de la distinción - B. Las implicaciones de la distinción - C. Los límites y alcances de la distinción - II. NOTAS CONCLUSIVAS - Referencias.

Cómo citar este artículo: Blanco Cortina, D. J. (Diciembre, 2014). Consideraciones sobre la verdad en el discurso normativo. Revista de Derecho Público, 33. Universidad de los Andes (Colombia).

** Abogado de la Universidad de Cartagena. Magíster en el derecho, perfil investigativo de la Universidad Nacional de Colombia, profesor ocasional de la misma universidad. Abogado de la Dirección Nacional de Estrategia en Asuntos Constitucionales de la Fiscalía General de la Nación. Investigador independiente. Correo blanco.cortina@gmail.com. 
Introducción

El tema de las relaciones entre derecho y verdad puede describirse con los siguientes adjetivos: viejo, recurrente y difícil. Los calificativos viejo y recurrente se sustentan entre sí de manera circular: el tema es viejo porque es recurrente y recurrente porque es viejo (aunque no necesariamente: un tema puede ser viejo, y no ser recurrente). Lo difícil se debe a la cantidad y complejidad de las discusiones que involucran la cuestión de la verdad tanto en la filosofía como en el derecho. Aquí solo habrá lugar para recoger algunas de las aristas que este problema reviste.

Pero, entonces, ¿por qué sigue siendo importante?, ¿por qué reviste interés un tema viejo?, ¿qué lo mantiene en vigencia? Baste señalar a este respecto tres razones normativas concatenadas: 1) la verdad es una de las vías mediante las cuales se puede garantizar un mínimo de justicia en los Estados constitucionales contemporáneos; 2) la ligereza con la que es tratado en ciertos círculos académicos que reniegan de todo lo que huela a positivismo, y abrazan un posmodernismo poco riguroso, lo cual obliga a una aproximación más sensata y menos folclórica del tema (Taruffo, 2010, pp. 89-98); y 3) solo teniendo un objeto común por conocer podemos resolver nuestros desacuerdos acerca de lo que es derecho y lo que no es, solo asumiendo algún parámetro de corrección podemos hablar de derecho, si no todo, absolutamente todo, se convierte en pura invención y cada quien podría decir lo que a bien tuviese sobre "lo que es conforme a derecho": el derecho se convertiría así en política, en una cuestión de poder. De allí el papel protagónico de la verdad en el derecho y la necesidad cada vez más apremiante de reflexionar sobre esta temática.

Así pues, la pregunta-guía que servirá de norte, y frente a la cual se avanzará una respuesta tentativa y preliminar es la siguiente: ¿en qué sentido podría hablarse de verdad en el derecho?

Las cursivas se deben a que ninguna de las dos expresiones puede ser usada en abstracto como si tuviese un contenido neutral y universal que se imponga a todos, sino que cada noción adquiere sentido a la luz de la concepción específica -filosófica o iusfilosófica- desde la cual se la define. Por ello, para entender la pregunta, debe indicarse en qué sentido se utilizan las expresiones verdad y derecho y bajo qué marco teórico.

En este orden, verdad será entendida aquí a la luz de los presupuestos de la teoría de la verdad como correspondencia. Presentada de modo esquemático, esta teoría señala que la verdad es un predicado que denota una propiedad sustancial de las aserciones, principalmente. La verdad en el contexto de esta teoría se construye a partir de las condiciones que nos habilitan a decir respecto de una afirmación que "es verdadera". El predicado "es verdadero" resulta característico de ciertos enunciados como los descriptivos, esto es, aquellos que describen fielmente un estado de cosas de la realidad.

En esta escueta presentación pueden apreciarse los tres elementos que componen esta con- 
cepción de la verdad: i) el portador de la verdad; ii) el correlato extralingüístico y iii) la relación de correspondencia. Cada uno de estos elementos ha generado discusiones acerca de cuál es la mejor forma de identificarlos o explicarlos separadamente. Sobre el primero algunos han sostenido que solo se puede predicar la verdad de los juicios. Otros han afirmado que las proposiciones, o bien han planteado que solo las oraciones, las expresiones lingüísticas o los enunciados son susceptibles de ser calificados como verdaderos (Sucar, 2008, pp. 105-114).

Así, en el ámbito de la filosofía analítica los autores han discutido sin fin sobre cuál es la mínima unidad lingüística de la que se puede afirmar su verdad y cuál es su naturaleza. Cada autor ha ofrecido sus argumentos para defender una de ellas, pero esta discusión no será reconstruida aquí, y a estos efectos bastará lo dicho en el párrafo precedente, puesto que para nuestra exposición asumiremos que los portadores de verdad son las proposiciones, conscientes, por demás, de que se trata de una cuestión discutible.

En cuanto al correlato extralingüístico se debe anotar que regularmente se entiende como hechos no lingüísticos que hacen parte de la realidad. Se han presentado dos discusiones a este respecto: 1) en un nivel ontológico: la realidad puede ser concebida como externa a la mente o, por el contrario, dependiente completamente de nuestra mente y nuestros esquemas representacionales. Lo primero daría lugar a una forma de realismo, lo segundo a un antirrealismo declarado, y entre ellas se pueden construir posiciones intermedias (cuasi realistas, por ejemplo).
La otra discusión representativa, conectada con la anterior, recae sobre la naturaleza de ciertas entidades que no serían necesariamente hechos, o por lo menos no en el sentido de hechos como acontecimientos o sucesos acaecidos en la realidad, como un accidente de tránsito o la Iluvia, sino que se cuestiona la presencia de otro tipo de hechos que podrían denominarse lingüísticos o institucionales, es decir, que dependen del lenguaje y que constituyen el mundo. Dicho de otro modo: no es el lenguaje intentando captar la realidad de los hechos brutos, sino que es el mundo (hechos institucionales) constituido por el lenguaje. Sin embargo, estos debates desbordan los límites de este trabajo.

Para los efectos que aquí interesan el correlato extralingüístico debe entenderse con las siguientes acotaciones: la idea de extralingüístico, literalmente, se refiere a algo externo a la estructura lingüística con la cual se elabora la proposición. Es decir, siempre debe haber lugar para la proposición, de un lado, y su referencia o significado, de otro, sin que se admita la posibilidad de que una proposición se refiera a sí misma.

La única limitación lógica, en este sentido, es que la proposición no debe nunca referirse a sí misma, sino que debe tener siempre una referencia externa a ella, sea cual fuere la naturaleza o el estatus de la entidad externa a la que se refiera. En consecuencia, expresiones del tipo "Yo miento" no configurarían una proposición genuina por cuanto sus condiciones de verdad se supeditan a sí misma (Cohen y Nagel, 1983, p. 18). 
La relación de correspondencia puede ser entendida de dos modos principalmente: a) como convención y b) como congruencia estructural o isomorfismo. Esta última forma de ver la relación implica la idea de que entre el lenguaje y el mundo existe una representación figurativa según la cual el lenguaje describe al mundo tal cual es. Por el contrario, la primera concepción defiende la noción de que cualquier palabra podría estar correlacionada con cualquier situación o estado de cosas, de acuerdo con las convenciones establecidas o que se puedan establecer (Sucar, 2008, pp. 112-4).

El isomorfismo estructural se encuentra íntimamente ligado a la concepción del atomismo lógico y la posibilidad de la construcción de un lenguaje ideal que pueda correlacionar invariablemente las palabras y expresiones con la disposición de los simples en el mundo, dando lugar a una relación única entre cosas o hechos y proposiciones. Debido a la estrechez de la metafísica que presupone esta forma de concebir la relación de correspondencia, no logra captar las dinámicas propias de un lenguaje tal como se ponen en juego en la vida cotidiana.

Frente a ello, la teoría convencionalista explica la correspondencia a partir de dos clases de convención: i) la "convención descriptiva" que correlaciona palabras con tipos de situaciones y ii) la "convención demostrativa", la cual pone en relación expresiones con situaciones específicas. En este marco de referencia, la correspondencia no depende del isomorfismo entre las palabras y el mundo (Haack, 1982, pp. 112-5).
Aunque no deja de presentar ciertos problemas, esta última concepción de la relación de correspondencia permite dar cuenta de ciertas clases de situaciones lingüísticas y comunicativas que se presentan en el lenguaje ordinario, las cuales serían imposibles de entender si asumimos el isomorfismo estructural. De allí que aquí se asuma la relación de correspondencia desde la perspectiva convencionalista.

Ahora bien, esta no es la única teoría sustancial o substantiva de la verdad defendible. Existen otras teorías alternativas como la pragmática o la coherentista, ambas fundadas sobre la idea de que la verdad solo puede ser entendida como "afirmabilidad justificada", esto significa que la verdad se predica de aquella aseveración que mejor justificada se encuentre en un contexto específico y cuya utilidad o coherencia se evidencie en relación con un discurso más amplio. De tal modo que resulta más adecuado hablar de creencias justificadas que podrían no ser verdaderas. Sin embargo, la que vale es su justificación y utilidad dado un contexto determinado, más allá de la verdad universal, difícilmente alcanzable (Rorty, 2007, pp. 19-23; 2007a, pp. 63-8).

Además, se pueden encontrar teorías deflacionarias de la verdad que niegan que el predicado "verdadero" denote una propiedad sustancial de aquellas afirmaciones que se califican como tal, sino que se trata, por el contrario, de un recurso retórico de ciertos poderes para ejercer controles sobre el "saber".

A pesar de este espectro teórico, cuando aquí se hable de verdad o se utilice el predicado "es 
verdadero" debe tenerse como marco teórico inmediato la teoría de la verdad como correspondencia con las implicaciones anotadas y las reservas planteadas sobre cada uno de sus elementos.

En resumen, los portadores de la verdad son las proposiciones que establecen una relación de correspondencia convencional con sus correlatos extralingüísticos, cuya única restricción consiste en que deben ser externos a las proposiciones mismas, esto es, nunca puede una proposición referirse a sí misma.

El otro elemento problemático y que requiere ser comentado es la voz derecho. El derecho puede ser entendido como un orden normativo justificado, como orden social o como orden autónomo que se autorregula (Aguiló, 2014, p. 6). En esta oportunidad, cuando se use esta expresión debe entenderse en dos sentidos interrelacionados: i) como orden normativo, esto es, como un conjunto de normas cuya finalidad es la de ser una guía práctica del comportamiento; y ii) como discurso normativo, es decir, como todas aquellas expresiones que califican deónticamente las conductas como prohibidas, permitidas $u$ obligatorias y que tienen una naturaleza estrictamente jurídica y no moral.

Así pues, se han especificado los términos que componen la pregunta. Es hora entonces de avanzar en la hipótesis que intentará ser reconstruida aquí para responder a la interrogación planteada: ¿en qué sentido se podría hablar de verdad en el discurso normativo?
La respuesta que se propone, como hipótesis de trabajo, es la siguiente: por lo menos, en dos contextos cabría hablar de verdad en el derecho, a saber: a) en el ámbito de las proposiciones normativas y b) en el campo de la prueba de los hechos en el proceso judicial o en el derecho probatorio, ${ }^{1}$ lo que se conoce regularmente como verdad procesal (Caracciolo, 2013, p. 13).

En este escrito solo se desarrolla la parte a) de la hipótesis de trabajo, debido tanto a la economía del espacio como a la fase primaria en la que se encuentra la investigación. Asimismo, cabe anotar que algunas implicaciones y presupuestos teóricos independientes que se derivan de cada elemento de la hipótesis, justifica provisionalmente su tratamiento por separado.

Para desarrollar lo relativo al tema de las proposiciones normativas se sigue el siguiente orden: en primer lugar, i) la discusión en torno a la distinción entre normas y proposiciones normativas; para luego, ii) revisar las implicaciones, consecuencia y alcances de la distinción. Por último, iii) se plantean algunos límites y problemas que aquejan la mentada distinción.

1 Este aspecto de la hipótesis de trabajo es el complemento de una hipótesis más amplia, que sostiene que en el razonamiento judicial pueden converger dos modelos de verdad complementarios que permitirian la evaluación de las premisas que componen el razonamiento. Estos modelos de verdad serían: el hermenéutico, que también podría ser llamado coherencial o retórico, y el modelo de verdad como correspondencia, asumiéndolo con algunas limitaciones centrales. El primero atendería las particularidades relativas a la premisa normativa y el segundo se ocuparía de la valoración de la premisa fáctica o menor del razonamiento judicial. Esta hipótesis integralmente considerada se expone en Blanco (2014, p. 8), sin ser desarrollada del todo. 


\section{LA DISPUTA POR LA DISTINCIÓN ENTRE NORMAS Y PROPOSICIONES NORMATIVAS}

\section{A. Las versiones de la distinción}

La distinción surge de una idea generalmente aceptada: las normas carecen de valores de verdad en la medida en que no describen el mundo, su función no es descriptiva sino enteramente prescriptiva: ordenan hacer algo. Por esta razón, de ellas se puede predicar su validez 0 invalidez, o su eficacia e ineficacia pero no verdad o falsedad. Estos últimos son predicados completamente extraños a la norma, aunque, valga la pena anotarlo, no han hecho falta autores que sostienen que se puede hablar de verdad en relación con las normas (Kalinoswki, 1979).

Sin embargo, puede hablarse de la existencia de cierta convergencia entre los autores en cuanto a que las normas carecen de valores de verdad. De allí que el dilema planteado por Jørgensen en los años 30 del siglo anterior todavía merezca atención: o bien las normas carecen de valores de verdad y entonces no existen relaciones lógicas entre ellas, o bien sí existen relaciones lógicas entre las normas, pero debemos reconsiderar la noción semántica tradicional de "consecuencia lógica" que asume que un razonamiento válido, en términos lógico-deductivos, es aquel en el que la verdad de las premisas se transfiere a la conclusión (Hernández-Marín, 2003, pp. 81-82; 2007, pp. 148-153).

De la forma como se resuelva el dilema dependerá la posición que se adopte acerca de si las relaciones entre las normas son de naturaleza lógica o no (Alchourrón y Martino, 1988, pp. 2426; Alchourrón, 1995, pp. 41-42). No obstante, este no es nuestro problema principal. La cuestión que ocupa nuestra atención radica en el hecho de que si bien las normas carecen de valores de verdad, las proposiciones normativas no.

Estas últimas, en la medida en que se refieren a la existencia o no de una norma dentro de un sistema jurídico determinado, cuentan con los tres elementos referidos anteriormente según la teoría de la correspondencia: i) un portador de verdad: la proposición normativa; ii) un correlato extralingüístico: la norma y iii) una relación de correspondencia: la pertenencia o no de una norma a un sistema jurídico. En estos términos, una proposición normativa puede ser susceptible de ser calificada como verdadera o como falsa de acuerdo con el sistema jurídico de que se trate.

Ahora bien, ¿cómo debe entenderse la disociación entre norma y proposición normativa?, ¿la existencia de una norma se reduce a la pertenencia a un sistema normativo-jurídico? Veamos las siguientes expresiones:

1. "Están prohibidas constitucionalmente las penas inhumanas y crueles".

2. "De acuerdo con el sistema jurídico colombiano, las penas crueles e inhumanas están prohibidas". 2

2 Obsérvese que la pertenencia de una norma a un sistema normativo, entendida la norma como el significado de una formulación normativa, es una cuestión distinta a la pregunta acerca de si la cadena perpetua, el ostracismo o la lapidación son castigos "inhumanos y crueles". Lo 
La primera enunciación evidencia la ambigüedad propia de esta clase de expresiones en la medida en que puede, bien referirse a una norma o bien referirse a una proposición normativa. Si es lo primero entonces no hay lugar a un calificativo de verdad o falsedad sobre ella, si es lo segundo correspondería a la forma elíptica de una proposición normativa.

Por el contrario, en el segundo enunciado se elimina la ambigüedad dado que responde a la estructura de una proposición normativa expandida, en la medida en que se explícita la referencia externa, a saber: el sistema jurídico colombiano (Buligyn, 2003, p. 81).

Al no reparar en estas sutilezas se ha incurrido en no pocas confusiones entre los autores que sostienen la inutilidad de la lógica para entender el derecho, asumiendo críticas injustificadas y planteamientos mal fundados que hacen poca justicia al valor del instrumental lógico para capturar aspectos cruciales sobre cómo funcionan los sistemas jurídicos. De allí que el profesor Rodríguez reclame mayor atención para la distinción y la revisión de sus implicaciones (2003, pp. 88-92).

De las afirmaciones como la 2) puede decirse que son falsas o verdaderas dependiendo de si en el sistema jurídico colombiano existe o no una norma que prohíba efectivamente las pe-

primero responde a la pregunta por la identificación de las normas de un sistema jurídico, mientras que lo segundo refiere un problema de aplicación o justificación jurídica. Ambos dependen, sin embargo, de la concepción de interpretación que se adopte. Más adelante se desarrollarán las diferencias y convergencias entre una y otra perspectiva. nas crueles e inhumanas. Así, podemos constatar que el artículo 12 de la Constitución de 1991 establece que "nadie será sometido a desaparición forzada, a torturas ni a tratos o penas crueles, inhumanos o degradantes". De allí que nuestra proposición resulte, por lo visto, verdadera. Pero entonces ¿cómo debe ser entendida la norma en tanto correlato de las proposiciones normativas?

\section{B. Las implicaciones de la distinción}

Alchourron y Bulygin (1991, pp. 251-252) han indicado que hay dos concepciones de las normas: la concepción hilética y la concepción expresiva. La primera considera que las normas son los significados de ciertas expresiones lingüísticas, a saber, las formulaciones normativas; mientras que la segunda concepción sostiene que las normas son el producto de cierto uso prescriptivo del lenguaje, y que solo en un contexto pragmático podemos determinar si estamos ante una norma, una aserción, una pregunta o cualquier otro "acto de habla".

No obstante, desde ambas concepciones se podría hablar de una lógica de proposiciones normativas, lo único que cambiaría sería la forma cómo se controla la relación de correspondencia entre la proposición normativa y la norma. Según la concepción hilética, para que una proposición sea verdadera se requiere que exista un significado normativo dentro del sistema jurídico que corresponda a lo señalado por la proposición, mientras que la visión expresiva de las normas exige que exista dentro del sistema un acto autoritativo que ordene, prohíba o permita la reali- 
zación de una conducta que venga expresada en disposiciones legales o constitucionales. ${ }^{3}$

Para ambas concepciones, en todo caso, es admisible la lógica de proposiciones normativas, es decir, enunciados que describen normas en términos de verdad o falsedad, relativas siempre a un sistema especificado -en la concepción expresiva se trataría de las formulaciones normativas o expresiones lingüísticas emitidas por una autoridad y en la hilética las normas serían los significados de las formulaciones normativas-.

Teniendo en cuenta que la diferencia entre una concepción y otra es gradual y de estilo, aquí se asumirá la concepción hilética, siendo esta la más difundida entre los autores y la que presenta menores problemas teóricos para dar cuenta de una lógica deóntica como lógica de proposiciones normativas (Bulygin, 1995, pp.132-134).

En este contexto teórico hay dos formas de presentar la distinción. La primera procede de las concepciones de lógica deóntica que remiten a Von Wright (1970), y cierto(s) positivismo(s) iusteóricos(s), la cual consiste en distinguir entre formulación normativa, norma y proposición normativa (Rodríguez, 2002, pp. 14-22).

La segunda deriva del realismo analítico italia-

3 De acuerdo con los profesores argentinos, la diferencia entre una y otra concepción es cuantitativa y no cualitativa, en la medida en que el criterio de selección termina inclinándose por cuestiones de estilo y de preferencias teóricas. Desde cada una de estas concepciones se pueden extraer los mismos réditos teóricos. Sin embargo, Bulygin ha señalado que la concepción expresiva presenta mayores inconvenientes teóricos para dar cuenta de una lógica de normas y una lógica de proposiciones normativas. De allí que no la considere una concepción teóricamente virtuosa. Cfr. Bulygin (1995, p.140). no y consiste en diferenciar entre disposición, norma y proposiciones normativas (Comanducci, 1992, pp. 91-94; 1999, pp. 30-33; Guastini, 1999, pp. 92-109; 2010, pp. 81-84). Ambas presentaciones parecen equivalentes y las diferencias resultan ser tan solo de términos, sin embargo, existen diferencias cualitativas entre una y otra presentación que responden a las distintas tradiciones iusfilosóficas de las que proceden.

Baste señalar lo siguiente: de acuerdo con la distinción -en cualquiera de sus dos versiones-, las formulaciones normativas o disposiciones son las expresiones lingüísticas utilizadas por el legislador ${ }^{4}$ para prescribir (prohibir, permitir u obligar) el comportamiento de los ciudadanos, pero la norma propiamente dicha surge de la interpretación que hacen los operadores jurídicos de las expresiones usadas por la autoridad competente para "crear derecho". Es decir, son los operadores jurídicos quienes "dan a luz" las normas mediante la atribución de significados a los enunciados que componen las disposiciones normativas.

Entonces, la existencia o no de una norma dependerá de cómo se conciba el proceso interpretativo de los operadores jurídicos, y esto repercutirá directamente sobre la posibilidad de hablar de proposiciones normativas en términos de verdad o falsedad. Aquí la cuestión se conec-

\footnotetext{
$4 \quad$ En las sociedades contemporáneas, el legislador está lejos de ser la única fuente del derecho, sin embargo sigue siendo la fuente predilecta por excelencia. Pero para simplificar el discurso se omite citar o señalar otras fuentes autoritativas de las que emana el derecho. Basta con remitir a la amplia literatura sociojurídica sobre el tema de la pluralidad jurídica, interlegalidad e incluso multiculturalidad. Cfr. Ardila (2002), Blanco (2012).
} 
ta con un tema tan o más debatido a nivel de teoría (o filosofía) del derecho ${ }^{5}$ que el problema de la verdad, a saber: la interpretación jurídica. Analicemos el panorama o espectro teórico sobre el particular.

Hay quienes suscriben las tesis del noble sueño, acuñando la terminología hartiana (Hart, 2000, pp. 329-337), en relación con la interpretación del derecho, esto es, quienes creen en la existencia de respuestas correctas en derecho para todos los casos. Estos autores no tienen problemas en hablar de proposiciones normativas por cuanto el intérprete siempre tendrá la posibilidad de determinar la respuesta correcta, y así, en todos los casos, se podrá hablar de proposiciones normativas falsas o verdaderas. Este grupo está conformado por los partidarios de la tesis de la única respuesta correcta à la Dworkin, para quien la interpretación es un ejercicio cognitivo (1999, p. 146).

En el extremo opuesto se encuentran quienes suscriben la posición de la pesadilla, es decir, los autores partidarios de la indeterminación radical del derecho, según la cual la interpretación es un proceso netamente discrecional y queda librado a las subjetividades de los operadores

5 No adscribimos aquí ninguna distinción sustancial entre teoría y filosofía para evitar explicaciones innecesarias que extenderían aún más el texto. Sin embargo, la concepción a este respecto coincide con la sostenida en Bobbio (1990), retomada por Guastini (1999, pp. 17-18), de acuerdo con la cual la única diferencia entre teoría y filosofía del derecho se encuentra en el nivel de abstracción con el que se abordan los problemas que preocupan a cada una: la primera se aproxima a los problemas desde la práctica del jurista (filosofía del derecho hecha por juristas), mientras que la segunda lo hace desde el plano conceptual filosófico (filosofía del derecho hecha por filósofos). Esta idea fue expuesta con mayores detalles en Blanco (2014, pp. 55-61). jurídicos. Para esta concepción la idea de proposiciones normativas es infundada por cuanto nunca se tiene la posibilidad de determinar con certeza si una norma pertenece o no al sistema jurídico. En este orden de ideas solo cabría hablar de disposiciones y normas.

Finalmente, encontramos a quienes sostienen la postura de la vigilia (Moreso 1997, p. 233). Estos autores consideran que existen casos fáciles en los que se puede determinar la respuesta correcta a partir del sistema normativo $y$, en consecuencia, respecto de ellos es posible determinar con certeza el correlato de las proposiciones normativas para establecer si es verdadera o falsa.

Pero también son frecuentes otra clase de casos, los difíciles, a la luz de los cuales la noción de proposición normativa resulta problemática, por cuanto no se puede especificar ciertamente cuál es el correlato de la proposición en la medida en que no hay una sola respuesta correcta, sino que pueden existir varias soluciones distintas, e incluso contradictorias, con el mismo grado de validez o corrección.

En este orden de ideas, tenemos que la utilidad del concepto de proposición normativa depende en todo de la concepción de interpretación jurídica que se asuma, comoquiera que para determinar la pertenencia o existencia de una norma dentro de un sistema normativo determinado se debe, en primer lugar, atribuir algún sentido o significado a las expresiones lingüísticas que componen las disposiciones normativas. 
En la medida en que el resultado de esta atribución de significado sea unívoco o no, se podrá determinar si la proposición normativa es verdadera o falsa, aplicando los principios lógicos de no contradicción y tercero excluido, o por el contrario se tendrá que hablar de proposiciones normativas que pueden resultar contradictorias, en el entendido de que pueden ser ambas verdaderas o falsas al mismo tiempo (en el caso de sistemas normativos inconsistentes e incompletos, como son la mayoría de los sistemas jurídicos reales), dando al traste en estos casos con los fundamentos de la lógica estándar tradicional.

\section{Los límites y alcances de la distinción}

De esta manera, se empieza a dar cuenta de las limitaciones y ajustes que requiere la noción de “proposición normativa” y, en tal virtud, la idea de verdad en el derecho parece eclipsarse progresiva y gradualmente.

En primer lugar habría que introducir distinciones ulteriores. Una de ellas entre pertenencia y aplicabilidad. Esto nos Ileva a contestar una pregunta formulada arriba: la existencia de una norma no puede depender únicamente de su pertenencia al sistema jurídico, por cuanto pueden existir normas que no pertenecen al sistema jurídico pero que, sin embargo, son aplicables a un determinado caso, y viceversa, normas que pertenecen al sistema, y no obstante ello, no son aplicables a casos específicos.

Ejemplos de lo primero son las remisiones de un sistema a otro, es decir, cuando existe una norma que remite a otro sistema jurídico para establecer la solución de un caso -normas aplicables que no pertenecen al sistema remitente, sino al sistema destinatario-. Y como ejemplo de lo segundo tenemos las normas en vacatio legis - normas que pertenecen al sistema pero no son aplicables por cuanto no han entrado en vigencia-(Navarro y Moreso, 1993, pp. 105-108).

Lo anterior conlleva otra distinción: esta vez entre el nivel identificatorio del derecho y el nivel justificatorio o, mejor, aplicativo del derecho. El primero se refiere a cómo identificar las normas jurídicas de un sistema jurídico, mientras que el segundo remite al problema acerca de cuáles son las normas aplicables para resolver un asunto específico a la luz de un sistema normativo.

Desde el nivel identificatorio se concibe el derecho como un macrosistema respecto del cual se pueden señalar las normas que lo componen o que a él pertenecen. Por su parte, desde el nivel aplicativo el derecho sería un microsistema, compuesto por aquellas normas que debe aplicar un juez al caso bajo estudio.

Con ello nuevamente se reafirma la tesis que se ha venido ventilando: no todas las normas aplicables por un juez pertenecen al sistema normativo dentro del cual se encuentra inserto, pero tampoco todas aquellas que pertenecen al sistema son aplicables por el operador jurídico. No obstante, ambos criterios (pertenencia y aplicabilidad) pueden funcionar en los distintos niveles para hacer verdaderas o falsas las proposiciones normativas. 
Sin embargo, la naturaleza o el estatus de las normas, a la luz de las consideraciones expuestas, no queda del todo claro. Si las normas son el producto de la interpretación, esto es, el significado atribuido por los operadores judiciales al enfrentarse con el texto normativo, entonces, ¿no hay normas previas a la aplicación judicial del derecho?

Las normas pertenecientes al sistema solo son viables luego de que las disposiciones o formulaciones normativas sean interpretadas y aplicadas. Ahora bien, si se entiende que la interpretación puede llevarse a cabo por parte de todos los operadores jurídicos -litigantes, dogmáticos, funcionarios públicos, jueces, etc.-, entonces las normas como correlato de las proposiciones normativas son indeterminables por cuanto habrá tantas normas como interpretaciones posibles, y en consecuencia la verdad de las proposiciones normativas sería indeterminable (!).

La estrategia que plantea Guastini (2010, pp. 145-154) parece ser la más efectiva para salir de esta encrucijada. Según el maestro italiano las proposiciones normativas entendidas como enunciados metalingüísticos sobre los textos interpretados -normas-, y no sobre las formulaciones normativas, solo son posibles en dos casos: a) cuando la interpretación de un texto normativo es dominante, esto es, cuando a pesar de ser controvertida es impuesta por alguna autoridad jurisdiccional; y b) cuando la interpretación es pacífica, es decir, cuando recae sobre el núcleo de significado normativo no controvertido de las formulaciones normativas.
Solo en estos dos eventos se puede establecer con certeza la verdad o falsedad de una proposición normativa. Pero el peligro de esta salida radica en que el sistema quedaría radicalmente indeterminado mientras estas dos situaciones no se presenten, lo cual es conceptual y prácticamente posible. Bajo este entendido el sistema, en cuanto tal, no podría cumplir con una de sus finalidades inmediatas como es la de regular la conducta de los individuos, en tanto que ello solo es posible a partir de directrices claras y normas identificables sin que medie la interpretación autoritativa previa (Hart, 1998, p. 155).

\section{NOTAS CONCLUSIVAS}

Lo anterior lleva a concluir que las proposiciones normativas solo serían posibles y útiles desde una cierta perspectiva: aquella que combina un punto de vista externo y una aproximación teórica al derecho para determinar las normas que lo conforman, pero desde un punto vista interno y una aproximación práctica al derecho, las proposiciones normativas tendrían un papel bastante limitado por cuanto cumplirían una función netamente orientativa mas no justificativa.

Esto significa que las proposiciones normativas servirían para identificar ciertas normas dentro de un sistema normativo pero no para resolver problemas prácticos, toda vez que de un enunciado descriptivo de normas no se pueden derivar conclusiones de "deber ser" que permitan decidir o bien justificar decisiones en algún sentido. ${ }^{6}$

6 De esto ya se había percatado el profesor Bulygin al señalar que una mera lógica de proposiciones normativas no basta para analizar el fe- 
Para justificar una decisión judicial se requieren normas que guíen el razonamiento práctico y no solo proposiciones normativas que indiquen cuáles normas pertenecen al sistema jurídico (micro o macro). Por tanto, el papel de la verdad queda limitado o restringido al nivel identificatorio y la aproximación teórica al derecho, en cuanto a la función cognoscitiva de las proposiciones normativas. Este planteamiento, incluso, desde cierta óptica, podría hacerse extensivo a la dogmática jurídica (Guastini, 2005, pp. 223224), aunque desde una visión quizá más flexible y enriquecida de la ciencia jurídica no sería del todo válido (Courtis, 2009, pp. 29-62).

Dicha función cognoscitiva debe ser complementada con una visión argumentativa que conciba el derecho como una actividad que se construye permanentemente desde la práctica, en un ejercicio retórico o dialéctico o pragmático (Atienza, 2006, p. 247 y ss.; Walton, 1990, pp. 411-417), yendo más allá de la concepción del derecho como un libro o sistema maestro lógico-deductivo en el que sus consecuencias están dadas de antemano, y solo necesitan ser explicitadas (Alchourrón, 2000, pp. 21-29).

Pero aun desde cualquiera de las perspectivas -la teórica/externa o la práctica/interna-, ante una situación de indeterminación jurídica, cuando el derecho habla con voz incierta (vaguedad de las expresiones normativas), con voces múltiples e incompatibles (contradicciones normativas) o cuando guarda silencio (lagunas normati-

nómeno de lo "jurídico" desde una perspectiva justificativa, sino que se requiere para completar el enfoque una lógica de normas propiamente dichas. Cfr. Bulygin (1995, p. 140). vas) (Moreso, 1997, pp. 87-116), las proposiciones no cumplen ningún rol de relevancia.

Para la resolución de situaciones problemáticas que se ubican en los márgenes de penumbra del sistema, en la medida que no sería posible determinar la falsedad o verdad de una proposición normativa, esta no podría más que ser una herramienta orientativa que no suministra ninguna respuesta con grado de certeza.

Dicho en otras palabras, las proposiciones normativas solo serían funcionales ante los "casos fáciles", es decir, aquellos en los que el sistema jurídico habla con "voz cierta". En tal virtud, la verdad quedaría así funcionalmente reducida a la clase de supuestos frente a los cuales la actividad interpretativa consistiría en un ejercicio cognoscitivo, no discrecional.

Para aquellos casos en los que el derecho habla con "voz penumbrosa", se debe recurrir a otros modelos de verdad que suministren parámetros de corrección, diferentes a los señalados por las concepciones discutidas en precedencia.

\section{Referencias}

Aguiló, J. (2014). Fuentes del Derecho. En Enciclopedia de Filosofía y Teoría del Derecho (Vol. II, págs. 1-53). México: Universidad Nacional Autónoma de México.

Alchourrón, C. (1995). Concepciones de la lógica. En C. Alchourrón (Ed.), Lógica, (págs. 1147). Madrid: Trotta. 
Alchourrón, C. (2000). Sobre derecho y lógica. Isonomía (13), 11-33.

Alchourrón, C., Bulygin, E. (1991). Análisis lógico y derecho. Madrid: Centro de Estudios Constitucionales.

Alchourrón, C. y Martino, A. (1988). Lógica sin verdad. Theoria, III(7-9), 7-43. Obtenido de Prof. A. A. Martino: http://www.antonioanselmomartino.it/index.php?option=com_conten t\&task=view\&id=42\&Itemid=88

Ardila, E. (2002). Pluralismo jurídico: apuntes para el debate. El otro Derecho (26-27), 4961.

Atienza, M. (2006). El derecho como argumentación. Barcelona: Ariel.

Blanco, D. (2014). Hacia una concepción pragmática de la ponderación [Tesis de Maestría], Universidad Nacional de Colombia. Bogotá.

Blanco, D. (2012). Los límites del multiculturalismo. Más allá del culturalismo liberal. Revista Diálogos de Derecho y Política (10), 1-27. Obtenido de Diálogos de Derecho y Política: http://aprendeenlinea.udea.edu.co/ revistas/index.php/derypol/article/viewFile/13372/11959

Bobbio, N. (1990). Naturaleza y función de la filosofía del derecho. En Contribución a la teoría del derecho (págs. 91-101). Madrid: Editorial Debate.
Bulygin, E. (1995). Lógica Deóntica. En C. Alchourrón (Ed.), Lógica (págs. 129-141). Madrid: Trotta.

Bulygin, E. (2003). El papel de la verdad en el discurso normativo. Doxa (26), 79-85.

Caracciolo, R. (2013). El problema de los hechos en la justificación de sentencias. Isonomía (38), 13-34.

Cohen, M. y Nagel, E. (1983). Introducción a la lógica y al método científico (t. I). Buenos Aires: Amorrortu Editores.

Comanducci, P. (1992). Principios jurídicos e indeterminación del derecho. Doxa (12), 89104.

Comanducci, P. (1999). Razonamiento jurídico. Elementos para un modelo. México: Distribuciones Fontamara.

Courtis, C. (2009). El juego de los juristas: ensayo de caracterización de la investigación dogmática. En Ecos cercanos: escritos sobre derechos humanos y justicia (págs. 17-90). Bogotá: Siglo del Hombre Editores.

Dworkin, R. (1999). Los derechos en serio. Barcelona: Ariel.

Guastini, R. (1999). Distinguiendo: estudios de teoría y metateoría del derecho. Barcelona: Gedisa. 
Guastini, R. (2005). Rigidez constitucional y normatividad de la ciencia jurídica. Isonomía (22), 223-228.

Guastini, R. (2010). Nuevos estudios sobre la interpretación. Bogotá: Universidad Externado de Colombia.

Haack, S. (1982). Filosofía de las lógicas. Madrid: Ediciones Cátedra S. A.

Hart, H. L. A. (1998). El concepto de derecho. Buenos Aires: Abeledo-Perrot.

Hart, H. L. A. (2000). Una mirada inglesa a la teoría del derecho norteamericana. Entre el noble sueño y la pesadilla. En J. Moreso y P. Casanovas (Eds.), El ámbito de lo jurídico: lecturas de pensamiento contemporáneo (págs. 327-350). Barcelona: Crítica.

Hernández-Marín, R. (2003). Sobre la concepción lógica del derecho. Isonomía (18), 79110.

Hernández-Marín, R. (2007). Los dos dilemas de Jörgensen. Analisi e diritto, 147-168.

Kalinowski, G. (1979). El problema de la verdad en la moral y el derecho. Buenos Aires: Eudeba.

Navarro, P. y Moreso, J. J. (1993). Orden jurídico y sistema jurídico. Madrid: Centro de Estudios Constitucionales.
Moreso, J. J. (1997). La indeterminación del derecho y la interpretación constitucional. Madrid: Centro de Estudios Políticos y Constitucionales.

Rodríguez, J. (2002). Lógica de los sistemas normativos. Madrid: Centro de Estudios Políticos y Constitucionales.

Rodríguez, J. (2003). Naturaleza y lógica de las proposiciones normativas. Contribución en homenaje a G. H. von Wright. Doxa (26), 87108.

Rorty, R. (2007). Universalidad y verdad. En R. Rorty y J. Habermas, Sobre la verdad: ¿validez universal o justificación? (págs. 9-80). Buenos Aires: Amorrortu.

Rorty, R. (2007a). ¿Para qué sirve la verdad? En R. Rorty y P. Engel, ¿Para qué sirve la verdad? (págs. 55-71). Barcelona: Paidós.

Sucar, G. (2008). Concepciones del derecho y de la verdad jurídica. Buenos Aires: Marcial Pons.

Taruffo, M. (2010). Notas acerca de la verdad en el proceso. En Simplemente la verdad (págs. 89-153). Madrid: Marcial Pons.

Von Wright, G. (1970). Norma y acción: una investigación lógica. Madrid: Editorial Tecnos.

Walton, D. (1990). What is reasoning? What is an argument? The Journal of Philosophy, LXXVII(8), 399-419. 